\title{
Empirical Study on Influencing Factors of Regional Innovation Output System-Take Qingyuan, Guangdong as an Example
}

\author{
Hui He ${ }^{1}$, Yibo Qin ${ }^{2}$, Huihui Deng ${ }^{1}$, Qi Gao ${ }^{3}$, Weitao Liu ${ }^{2, *}$ \\ ${ }^{1}$ Research Department, Qingyuan Polytechnic, Qingyuan, China \\ ${ }^{2}$ Guangzhou Urban Strategy Institute, Guangzhou Academy of Social Sciences, Guangzhou, China \\ ${ }^{3}$ Research Department, Guangdong University of Foreign Studies, Guangzhou, China
}

Email address:

cyllwt@aliyun.com (Weitao Liu)

${ }^{*}$ Corresponding author

\section{To cite this article:}

Hui He, Yibo Qin, Huihui Deng, Qi Gao, Weitao Liu. Empirical Study on Influencing Factors of Regional Innovation Output System-Take Qingyuan, Guangdong as an Example. International Journal of Business and Economics Research. Special Issue: Microfinance and Local Development. Vol. 9, No. 1, 2020, pp. 40-49. doi: 10.11648/j.ijber.20200901.15

Received: October 23, 2019; Accepted: January 28, 2020; Published: February 13, 2020

\begin{abstract}
The construction of regional innovation system is an important direction for modern cities and regional economic development and industrial transformation. Based on the existing research results, this paper selects relevant data of Qingyuan from 2001 to 2017, and uses patent authorization, output value of high-tech products and total export value as the evaluation system of regional innovation output to build a regional innovation system model including five influencing factors such as research and development investment, economic structure, infrastructure, opening level and innovation policy. With the help of SPSS software, the conclusions are drawn through principal component analysis that the selected factors have significant positive effects on the innovation output of Qingyuan, and the infrastructure, economic structure and the level of opening to the outside world have the greatest impact, with a smaller impact coefficient on R\&D investment. This shows that Qingyuan's ability to attract high-quality funds and advanced technologies needs to be strengthened, infrastructure construction needs to be further improved, and scientific research efficiency should be improved. In view of the above conclusions, this paper finally puts forward corresponding policy recommendations. In the future, Qingyuan municipal government should speed up the infrastructure construction focusing on transportation and logistics, give appropriate research and development subsidies to local enterprises, improve the efficiency of local enterprises in introducing advanced science and technology from Guangzhou, and better grasp the integrated development mode of Guangzhou and Qingyuan.
\end{abstract}

Keywords: Regional Innovation System, Principal Component Analysis, Qingyuan Guangdong

\section{Introduction}

As an important factor in economic and social development, innovation is a strong driving force for achieving long-term high-quality economic development in a region, and it is also the main driving force for promoting benign competition in the market, upgrading of products and industrial structures. The innovation capacity of a region often represents the level of regional economic development, corporate vitality and market competition. The close relationship between innovation capability and regional economic development has gradually become one of the research hotspots. The Outline of the National Medium- and Long-Term Science and Technology Development Plan proposes that each region should build a regional innovation system with its own characteristics and advantages. The construction of a regional innovation system must first meet the overall strategic goals of the country's economic development, and at the same time be differentiated according to the regional characteristics. Different levels of economic development and social environment between different regions, such as geographic topography, cultural atmosphere, transportation infrastructure, labor quality, capital adequacy, and industrial structure, all lead to a differentiated economic structure. In recent years, 
many scholars have conducted extensive research on the status of China's regional innovation system by using national statistical data as well as provincial and municipal data.

Qingyuan City is located in the central and northern part of Guangdong Province, which is the border area of Guangdong, Hunan and Jiangxi provinces. It has natural geographical transportation advantages. However, Qingyuan's main economic growth point is agriculture and traditional industries, mainly ceramic and cement manufacturing. Compared with Guangzhou and Shenzhen, Qingyuan's high-tech industry and service industry are lagging behind. In February 2019, the "Guangdong-Hong Kong-Macao Greater Bay Area Development Plan" was officially released. Qingyuan Municipal Committee proposed that Qingyuan, as the closest city to Greater Bay Area, should seize the opportunity of revitalization and development, highlight its own characteristics, reconstruct industrial transformation and upgrading, stimulate scientific and technological innovation, strengthen cooperation between Guangzhou and Qingyuan, and actively integrate into the construction of Greater Bay Area. In this context, this paper combines the regional characteristics and development direction of Qingyuan, collects and collates relevant economic data of Qingyuan from 2001 to 2017, and establishes an influencing factor analysis model including R\&D (Research and Development) investment, economic structure, infrastructure, openness and innovation policy. In terms of regional innovation output evaluation, it is represented by three dimensions: scientific and technological achievements, economic benefits, and regional competitiveness. On this basis, Principal Component Analysis (PCA) is used to objectively empower selected indicators to avoid subjective factors such as expert scoring, and regression analysis is also used to analyze the influencing factors and effects of Qingyuan's regional innovation system.

\section{Literature Review}

\subsection{Research on the Connotation of Regional Innovation System}

The concept of Regional Innovation System (RIS) was originally proposed by Cooke $[1,2]$, which is an regional organization system with interactive learning models consisting of innovative entities such as manufacturing companies, research institutions and higher education institutions in a rooted institutional environment. Cooke [2] also divided the regional innovation system into regions with strong development potential, regions with medium development potential and regions with no development potential based on the survey of 11 regions in Europe. Later, Asheim \& Isakson [3] divided the regional innovation system into two modes based on the perspective of the differentiated function of regional innovation system. One is the regional national innovation system, that is, the regional innovation model is subordinate to the national innovation model, with technology industrial parks as the representative; the other is the local innovation system rooted in the local industry with the industrial structure and system of their own characteristics. Domestic scholars Chaoqing Yuan and Sifeng Liu [4] based on the perspective of input-output efficiency of regional innovation, introduced the evaluation index of maturity of regional innovation system, classified the comprehensive efficiency of innovation input-output and maturity of innovation system into "high", "medium" and "low" respectively, and divided the regional innovation systems of 31 provinces in China into 8 types by permutation and combination, but as Song Wang et al. [5] summarized the connotation of the regional innovation system, the regional innovation system includes four main aspects: that is, the regional innovation system needs to include enterprises, government, research institutions and other subjects; the regional innovation system needs to rely on resources such as technology, manpower, and capital; the regional innovation system includes innovation of systems, management, technology, and etc.; the regional innovation system includes the output of product innovation, industrial innovation and environmental innovation.

\subsection{Research on the Influencing Factors of Regional Innovation System}

Research on the influencing factors of regional innovation systems has always been the focus of scholars. It has been widely believed that R\&D investment, economic structure, infrastructure, openness and innovation policy support are all important factors in promoting regional innovation.

Triguero [6] pointed out that the output efficiency of enterprises will be affected by the innovation activities in the early stage, and the R\&D investment and innovation output are the processes of continuous mutual promotion. Frank [7] believes that R\&D investment aimed at expanding the market is more conducive to the innovation output of enterprises. Xielin Liu and Lingfei Tian [8] pointed out that for different regions, increasing $R \& D$ investment in industries that are conducive to their own development is very important for regional innovation output and economic development. R\&D investment generally includes both input from $R \& D$ personnel and R\&D funding. Xibao [9] pointed out that R\&D resources such as capital and human capital are important input factors affecting innovation output.

Regional economic structures also show strong differentiation based on geographic location and regional policies. For example, Shulin Liu and Zhijian Hu [10] pointed out that in the study of the evolution of China's regional innovation capability, after the reform and opening up, the southeast coastal areas have the advantages of their geographical location, the tradition of commodity trade, the poor-base-and-small-burden of old industry. With the support of opening-up policies and other reasons, it gradually forms a more optimized industrial economic structure than the northwest region. Therefore, it is in a leading position in regional innovation output and economic growth, and industrial structure differences will also affect the efficiency of innovation input and output. 
Numerous studies have shown that infrastructure has a positive impact on regional innovation. Cook [11] suggests that the efficiency of regional innovation systems is influenced by infrastructure and government policies. Domestic scholars Shi Su and Zhouzhou Lin [12] studied the spatial effects of regional innovation, established a spatial matrix of traffic horizontal distance, and explored the impact of transportation infrastructure on regional innovation activities, and believed that the government should strengthen infrastructure construction and improve the information exchange and shared carriers, providing good internal conditions for promoting regional innovation.

Xielin Liu and Zhijian $\mathrm{Hu}$ [8] believe that opening up and attracting foreign investment are important means to improve regional technological innovation. As a developing country, China has introduced a certain level of overseas advanced technology while attracting foreign direct investment from overseas in the process of marketization. Therefore, foreign direct investment is of great significance to improving regional innovation capability. Wenguang Bo [13] pointed out that FDI will not significantly promote the level of regional technological innovation, and there are obvious regional characteristics, such as the impact of FDI on innovation in the eastern region is greater than that in the central and western regions. Fengqi Sun and Zhiwei Tian [14] used the network DEA method to measure the regional innovation efficiency and found that foreign trade opening can effectively exert the innovative competition effect and technology spillover effect in the knowledge innovation stage, and promote the comprehensive efficiency of regional innovation.

Many scholars believe that concept and institutional innovation are important factors influencing the regional innovation system, and the rapid rise of the southeastern region is driven precisely by the guidance and support of innovation policy. Xianghua Wang et al. [15] used the "Solow residual value method" to construct a model and analyzed the impact of regional government science and technology input on innovation output. The analysis believes that developed regions should strengthen the government's financial support for science and technology projects, and based on the high opportunity cost generated from government's science and technology funds investment, the efficiency of funding input and output should be strictly monitored, forming a benign cycle between the regional innovation system and government financial support.

\subsection{Research on Regional Innovation Output}

In the existing literature, the evaluation indicators of regional innovation output are mostly expressed by the number of patent applications. For example, Guoming Xian and Wenguang Bo [16] selected the number of patent applications to characterize the level of technological innovation when studying the impact of foreign direct investment on the technological innovation of Chinese enterprises [17-18]. However, the number of patent applications and the number of grants cannot fully describe the level of innovation output in the region, because the level of patents is largely an extension of the knowledge and technological innovations, many innovations in basic research or in the upgrading of products are not patented, but directly applied to further research or enterprise production. Therefore, some scholars began to introduce indicators of the output value of new products in the empirical study. For example, Xielin Liu and Lingfei Tian [8] believe that the gradual rise of high-tech industries will promote regional innovation efficiency. The high-tech industry is an important way to achieve regional economic revitalization, and is conducive to the development of regional innovation resources. It is an important indicator for enhancing patent innovation capability, patent transformation capability and innovation output capability. Further, the improvement of innovation efficiency and innovation output level will ultimately be reflected in regional competitiveness. Only in this way can R\&D resources investment and innovative technology investment gain production advantages [19-20].

\subsection{Review Comments}

At present, the existing literature mainly focuses on the definition, research scope and influencing factors of regional innovation system. This article focuses on the impact of regional innovation system on regional economic development model and industrial structure upgrading. At the same time, the article comprehensively considers the index selection methods of the existing literature, and establishes an empirical research model including five primary influencing factors and seven secondary influencing factors, aiming at a more comprehensive understanding of Qingyuan's regional innovation capability. On this basis, the article pays more attention to providing feasible policy suggestions to the government.

\section{Construction of Influencing Factors Analysis Model of Regional Innovation System}

Based on the existing research, this paper refers to and improves other literature methods, and selects five factors (including seven secondary impact factors) such as R\&D investment, economic structure, infrastructure, openness and innovation policy, and adopts scientific and technological achievements, economic benefits and regional competitiveness to represent regional innovation output levels, and construct an influencing factors analysis model of regional innovation systems.

\subsection{Regional Innovation System Factors Variable Selection}

\subsection{1. $R \& D$ Investment}

The input of R\&D resources directly affects the level of final innovation output. $R \& D$ resources generally include $R \& D$ expenditures and $R \& D$ personnel, i.e. $R \& D$ investment and manpower input. In general, $R \& D$ expenditures and 
personnel input are positively correlated with regional innovation output levels. It can be considered that the more abundant R\&D expenditures and researchers, the higher the level of innovation. Most of the literature selects $R \& D$ investment as the index, but this paper intends to select R\&D investment of enterprises above designated size (large and medium-sized enterprises) as a substitute for R\&D investment. Because the company is at the core of the regional innovation system, and the company is also directly involved in the market, it has the most timely and effective market information and product feedback. At the same time, the company's R\&D investment has a clearer goal: to improve the level of innovation output, improve the product quality connotation, and enhance the competitiveness of enterprises. Relatively speaking, the efficiency of enterprise R\&D investment is higher. Finally, corporate R\&D investment can be applied to product production as soon as possible, and its time lag is shorter than other research institutions and higher education institutions.

\subsubsection{Economic Structure}

An important aspect of the regional economic structure is the industrial structure, that is, the proportion of regional heavy industry and light industry. Considering that heavy industry is generally a large and medium-sized enterprise, it contains a large number of high-tech industries, and has a certain scale economy in commodity exports. Such enterprises have a relatively large industrial system, relatively strong capital, and the ability to purchase advanced large-scale mechanical equipment and precision instruments and meters, and it is easier to reach technical cooperation with international advanced enterprises. Therefore, this paper selects the ratio of regional heavy industry output value to regional industrial output value as a substitute indicator of economic structure.

\subsubsection{Infrastructure}

Infrastructure includes transportation infrastructure for cargo transportation and telecommunications infrastructure for information transmission. It is a carrier for regional innovation activities and information exchange. Generally speaking, the more complete the transportation infrastructure and the more developed the logistics and transportation, the more convenient the transportation, the easier the circulation of innovative products, and the lower the transaction cost of the products. The more developed the telecommunications network and the wider the coverage, the smoother the sharing of knowledge and information. It is beneficial to reduce the transaction cost of information. Therefore, this paper selects two indicators of the total social freight volume and the total volume of post and telecommunications services to represent the infrastructure factors.

\subsubsection{Degree of Openness to the Outside World}

The level of opening up to the outside world can reflect the regional exchanges, ideological innovations, and the ability to absorb foreign capital and advanced technologies to a certain extent. The regional freeness and openness in the conception and the trade is conducive to the flow of enterprise production factors and innovative technology information, and it will be benefit for enterprises and society to achieve more optimized resource allocation. The actual amount of foreign direct investment (FDI) can directly reflect the ability of enterprises in a region and its scope to absorb foreign capital. This ability also reflects the trade and exchange between the region and other regions or countries, which can be understood as the degree of openness of each other in the region. Therefore, this paper chooses FDI to indicate the degree of opening to the outside world.

\subsubsection{Innovation Policy}

Although China's southeast coastal areas have geographical advantages, their economic rise relies to a large extent on the guidance of the reform and opening up policy. As a guide for regional development, the government has various measures such as policy formulation, tax regulation, financial allocation, supervision and management to intervene in regional innovation output levels. Especially for some backward areas where some high-tech industries have just started, government guidance and financial support are crucial factors influencing the development and improvement of their innovation systems. Therefore, this paper selects the ratio of government financial science and technology allocation to fiscal expenditure as an indicator to measure innovation policy.

Table 1. Selection and Value of RIS Influence Factors Variables.

\begin{tabular}{lllll}
\hline Influence & Influencing Factors & Value & Variables \\
\hline \multirow{2}{*}{ R\&D Investment } & R\&D expenditures Input & $\begin{array}{l}\text { R \& D Expenditure of Industrial Enterprises above Designated Size } \\
\text { (RMB10,000 Yuan) }\end{array}$ & $\mathrm{X}_{1}$ \\
& R\&D Personnel Input & $\begin{array}{l}\text { Number of R \& D Personnel of Industrial Enterprises above Designated Size } \\
\text { (RMB10,000 Yuan) }\end{array}$ & $\mathrm{X}_{2}$ \\
Economic Structure & Industrial Structure & $\begin{array}{l}\text { Heavy Industry Output Value as a Percentage of Regional Industrial Output } \\
\text { Value (\%) }\end{array}$ & $\mathrm{X}_{3}$ \\
& Cargo Transportation Carrier & $\begin{array}{l}\text { Total Social Freight Volume } \\
(10,000 \text { Metric Tons) }\end{array}$ & $\mathrm{X}_{4}$ \\
Infrastructure & Information Knowledge & $\begin{array}{l}\text { Total Post and Telecommunications Business (RMB10,000 Yuan) } \\
\text { Carrier }\end{array}$ & $\begin{array}{l}\text { Actual Use of Foreign Direct Investment (USD 10,000) } \\
\text { Government Science and Technology Expenditures as a Percentage of Fiscal }\end{array}$ & $\mathrm{X}_{6}$ \\
Innovation Policy & Foreign Direct Investment & Government's Supporting Policy & \begin{tabular}{l} 
Expenditure (\%) \\
\hline
\end{tabular}
\end{tabular}


Based on the existing literature methods and the availability of data in Qingyuan, seven secondary indicators were selected to reflect the influencing factors of the regional innovation system. The specific indicators are shown in Table 1.

\subsection{Selection of Regional Innovation Output Evaluation Indicators}

\subsubsection{Scientific and Technological Achievements}

Scientific and technological achievements are the indicators that best reflect the ability of technological innovation. The number of patents can reflect the scale of scientific and technological activities and technological strength in the region. China's patents are divided into three categories: invention patents, utility models and designs. Some literature will be studied separately, but this paper does not make a specific distinction. The unified use of patent grants represents scientific and technological achievements to measure one aspect of regional innovation outputs.

\subsubsection{Economic Benefits}

As a result of regional technological innovation, it will be implemented in enterprise production and integration into product upgrades, and ultimately reflected in the improvement of regional economic benefits. Throughout the development of various industries, the relationship between high-tech industries and innovation is the closest, and it is also the industry with the most internalized knowledge innovation and technological innovation. At the same time, as China enters the critical period of reform for conversing old capacity to new driving force, more and more technological innovation achievements has flowed in the high-tech industry whose position in the regional economic development has gradually improved. This paper selects the output value of high-tech products as the proxy indicator of regional economic benefits. Due to the availability of data, this paper refers to the existing literature and the definition of high-tech manufacturing industry in the statistical bulletin of Guangdong Science and Technology Funds, selecting the total output value of information chemicals manufacturing, pharmaceutical manufacturing, aerospace manufacturing, electronics and communications equipment manufacturing, electronic computer and office equipment manufacturing, medical equipment and instrumentation manufacturing as the output value of high-tech products.

\subsubsection{Regional Competitiveness}

This paper believes that the regional innovation system should include 3 processes, i.e. innovation results obtained from $R \& D$ investment, applied to enterprise production and finally gain market recognition. Innovations and enterprise production have been expressed through scientific and technological achievements and economic benefits, while innovation output can be expressed through regional competitiveness through market recognition. The ability of regional innovation output should accept a wide range of market evaluations. For current Chinese companies, the international market often means higher product quality requirements and technological innovation requirements. Therefore, this paper selects the regional export trade volume as the proxy variable of regional competitiveness.

Table 2. Regional Innovation Output Evaluation Index.

\begin{tabular}{lll}
\hline Innovative Output & Value & $\begin{array}{l}\text { Variable } \\
\text { Symbol }\end{array}$ \\
\hline $\begin{array}{l}\text { Technological } \\
\text { Achievements }\end{array}$ & $\begin{array}{l}\text { Total Patent Authorization (Piece) } \\
\text { Output Value of High-tech } \\
\text { Economic Benefit }\end{array}$ & $\begin{array}{l}\text { Products (RMB100 million Yuan) } \\
\text { Total Export Trade Volume (USD }\end{array}$ \\
$\begin{array}{ll}\text { Regional } \\
\text { Competitiveness }\end{array}$ & $\mathrm{C}$ \\
\hline
\end{tabular}

\section{Empirical Analysis of Influencing Factors of Regional Innovation System}

\subsection{Data Source and Processing}

\subsubsection{Data Source Description}

This paper selects the data of innovation input and output of Qingyuan from 2001 to 2017 as an empirical analysis sample. The main data comes from "Qingyuan Statistical Yearbook", "Qingyuan National Economic and Social Development Statistical Bulletin" and "Guangdong Province Statistical Yearbook". Some of the data comes from the "Guangdong Province Science and Technology Funds Investment Statistics Bulletin". In addition, due to the lack of part of the data on science and technology appropriation project in fiscal expenditure, it is calculated and supplemented by the amount and growth rate of the appropriation funds in other years.

\subsubsection{Data Processing}

First of all, used the annual average exchange rate of the RMB to the US dollar in the current year, the indicator of the statistical unit of " 10,000 US dollars" is uniformly converted into " 10,000 yuan". At the same time, in order to give the data more reference value, this paper uses the total consumer price index to reduce the impact of the price on the data.

Secondly, this paper considers the time lag between innovation input and innovation output, that is, it can be considered that the input of innovation activities and policy application will have an impact on the next stage of innovation output. Therefore, the sample of regional innovation influencing factors in this paper uses 2001-2016 data, and the innovation output evaluation data uses 2002-2017 data [19], [21].

Finally, because there are many different units of measurement for data, it is difficult to conduct comprehensive comparative analysis, so the data needs to be dimensionless. According to the prior literature, the means of averaging is a more common method, that is, each variable is divided by the average of the variable. The mean method can better preserve the original information and difference of the data while eliminating the dimension of the variable, and ensure the comparability of the data.

The processed data is described as follows: 
Table 3. Data Descriptive Statistics.

\begin{tabular}{llllll}
\hline Variables & Observations & Minimum & Maximum & Mean & Standard Deviation \\
\hline $\mathrm{X}_{1}$ & 17 & 0.0087 & 2.4852 & 1.0000 & 1.0301 \\
$\mathrm{X}_{2}$ & 17 & 0.0045 & 2.8041 & 1.0000 & 1.0436 \\
$\mathrm{X}_{3}$ & 17 & 0.8450 & 1.0918 & 1.0000 & 0.0821 \\
$\mathrm{X}_{4}$ & 17 & 0.4266 & 1.8266 & 1.0000 & 0.5026 \\
$\mathrm{X}_{5}$ & 17 & 0.3062 & 2.1721 & 1.0000 & 0.4875 \\
$\mathrm{X}_{6}$ & 17 & 0.3284 & 2.0694 & 1.0000 & 0.5797 \\
$\mathrm{X}_{7}$ & 17 & 0.0004 & 1.8501 & 0.9486 & 0.4374 \\
$\mathrm{~T}$ & 17 & 0.1083 & 3.9713 & 1.0000 & 1.1481 \\
$\mathrm{E}$ & 17 & 0.0457 & 2.6252 & 1.0000 & 0.7290 \\
$\mathrm{C}$ & 17 & 0.1930 & 1.5249 & 1.0000 & 0.4456 \\
\hline
\end{tabular}

On this basis, we have made reliability statistics for all 10 variables. Clonbach Alpha coefficient reaches 0.872, which means that the selected variables have good reliability.

Table 4. Reliability Test

\begin{tabular}{ll}
\hline Cronbach (Alpha) & item \\
\hline 0.872 & 10 \\
\hline
\end{tabular}

\subsection{Variable Analysis of Comprehensive Evaluation of Regional Innovation Output}

This paper selects scientific and technological achievements ( $T$ ), economic benefits ( $E$ ) and regional competitiveness $(C)$ to jointly evaluate regional innovation output levels. First check the correlation between the three variables. Through SPSS correlation analysis, this paper finds that although there is no strong correlation level between the three, there is still a statistically significant correlation. The correlation coefficient between the pair $T$ and $C$ reaches 0.70 , and the correlation coefficient between $E$ and $C$ is also 0.74 , which is enough to explain that there is a correlation between them, that is, there is information overlap. In order to further eliminate the multicollinearity caused by correlation between the three, and compress the variables to facilitate subsequent regression analysis, this paper replaces the original three variables with one variable by means of objective weighting. Using SPSS software, based on the variance contribution rate of principal

$$
Y_{t}=\beta_{0}+\beta_{1} X_{1, t-1}+\beta_{2} X_{2, t-1}+\beta_{3} X_{3, t-1}+\beta_{4} X_{4, t-1}+\beta_{5} X_{5, t-1}+\beta_{6} X_{6, t-1}+\beta_{7} X_{7, t-1}+\varepsilon
$$

Among them, $\beta_{0}$ is a constant term, $\beta_{i}$ is a partial regression coefficient, $t$ represents a time series which is from 2002 to $2017, \varepsilon$ indicates a disturbance term which is an unobservable random error caused by other factors. component analysis as the weight, the comprehensive dependent variable $Y$, which is composed of scientific and technological achievements ( $T$ ), economic benefits $(E)$, and regional competitiveness $(C)$, is obtained:

$$
Y=0.363 T+0.374 E+0.403 C
$$

\subsection{Empirical Analysis of Influencing Factors of Regional Innovation System}

This paper starts with 5 influencing factors and establishes 7 secondary impact factors, which are R\&D expenditures of industrial enterprises above designated size $\left(X_{1}\right)$, R\&D personnel of industrial enterprises above designated size $\left(X_{2}\right)$, and heavy industry output value as a percentage of regional industrial output value $\left(X_{3}\right)$. total social freight volume $\left(X_{4}\right)$, total post and telecommunications business $\left(X_{5}\right)$, actual use of foreign direct investment $\left(X_{6}\right)$, government science and technology expenditures as a percentage of fiscal expenditure $\left(X_{7}\right)$. The multivariate linear regression model of the influencing factors of the regional innovation system is constructed by the comprehensive dependent variable and the seven influencing factors and obtained by formula (1), as follows:
Still considering the existence of multicollinearity between independent variables, in order to avoid the error of regression, the correlation between variables is tested by SPSS software.

\begin{tabular}{|c|c|c|c|c|c|c|c|}
\hline Variable & $\mathbf{X}_{1}$ & $\mathbf{X}_{2}$ & $\mathbf{X}_{3}$ & $\mathbf{X}_{4}$ & $\mathbf{X}_{5}$ & $X_{6}$ & $\mathbf{X}_{7}$ \\
\hline $\mathrm{X}_{1}$ & 1.000 & $0.962 * * *$ & $0.819 * * *$ & $0.889 * * *$ & $0.345^{*}$ & $-0.431 * *$ & $0.808 * * *$ \\
\hline $\mathrm{X}_{2}$ & $0.962 * * *$ & 1.000 & $0.739 * * *$ & $0.931 * * *$ & $0.426^{* *}$ & $-0.521 * *$ & $0.789 * * *$ \\
\hline$X_{3}$ & $0.819 * * *$ & $0.739 * * *$ & 1.000 & $0.774 * * *$ & $0.566 * * *$ & -0.013 & $0.724 * * *$ \\
\hline $\mathrm{X}_{4}$ & $0.889 * * *$ & $0.931 * * *$ & $0.774 * * *$ & 1.000 & $0.623 * * *$ & $-0.424 * *$ & $0.828 * * *$ \\
\hline $\mathrm{X}_{5}$ & $0.345^{*}$ & $0.426^{*}$ & $0.566 * * *$ & $0.623 * * *$ & 1.000 & 0.012 & $0.579 * * *$ \\
\hline$X_{6}$ & $-0.431 *$ & $-0.521 *$ & -0.013 & $-0.424 *$ & 0.012 & 1.000 & $-0.421 * *$ \\
\hline$X_{7}$ & $0.808 * * *$ & $0.789 * * *$ & $0.724 * * *$ & $0.828 * * *$ & $0.579 * * *$ & $-0.421 * *$ & 1.000 \\
\hline
\end{tabular}
The results are as follows:

Table 5. Correlation Coefficient Matrix.

Note: The significance level $*$ is $\mathrm{p}<0.1, * *$ is $\mathrm{p}<0.05, * * *$ is $\mathrm{p}<0.01$ 
Table 5 shows the correlation coefficients between the selected variables. It can be seen that except for the fact that the actual use of the direct investment is not relevant, there is a strong correlation between other variables and it is statistically significant. Thus, it can be considered that there is severe collinearity between the variables. Further, in order to eliminate the influence of the multi-collinearity existing between the variables on the regression analysis, the seven variables $X_{1}-X_{7}$ are implemented by SPSS software to perform principal component analysis to compress the number of variables.

Table 6. Principal Component Analysis.

\begin{tabular}{llllll}
\hline & \multicolumn{2}{l}{ Initial Eigenvalue } & & \multicolumn{2}{c}{ Extracting the Sum of Squared Loads } \\
\hline Component & Total & Variance\% & Accumulation\% & Total & Variance\% \\
\hline 1 & 4.822 & 68.889 & 68.889 & 4.822 & 68.889 \\
2 & 1.184 & 16.914 & 85.802 & 1.184 & 16.914 \\
3 & 0.603 & 8.618 & 94.420 & & \\
4 & 0.221 & 3.154 & 97.574 & & \\
5 & 0.115 & 1.640 & 99.214 & & \\
6 & 0.044 & 0.635 & 99.849 & & \\
7 & 0.011 & 0.151 & 100.000 & & \\
\hline
\end{tabular}

Table 6 shows that after principal component analysis of all variables, two main components can be extracted, and the cumulative variance contribution rate reaches $85.802 \%$. That is, the selected two principal components can be considered to cover most of the information of all influencing factors.
Furthermore, the expressions of the selected two principal components can be calculated according to the load coefficients of the respective variables, and the two principal components are $F_{1}$ and $F_{2}$ :

$$
\begin{gathered}
F_{1}=0.195 X_{1}+0.197 X_{2}+0.175 X_{3}+0.2 X_{4}+0.126 X_{5}-0.092 X_{6}+0.188 X_{7} \\
F_{2}=-0.113 X_{1}-0.156 X_{2}+0.316 X_{3}+0.006 X_{4}+0.473 X_{5}+0.696 X_{6}+0.003 X_{7}
\end{gathered}
$$

Since the expression of the principal component variable is obtained, the variable in the equation (2) can be replaced by the comprehensive variables $F_{1}$ and $F_{2}$ and subjected to regression analysis, because the comprehensive variables do not have the collinearity with the independent variables, and the estimation error of the regression coefficient is avoided. From this, the result is as follows:

$$
Y_{t}=\beta_{0}+\delta_{1} F_{1, t-1}+\delta_{2} F_{2, t-1}+\varepsilon
$$

In the formula (5), $\beta_{0}$ is a constant term, $\delta_{1}$ and $\delta_{2}$ is a partial regression coefficient of the principal component $F_{1}$ and $F_{2}, t$ is a time series (2002-2017) and $\mathcal{E}$ is an error term.

Regressed by SPSS software, a constant term coefficient of 0.159 is yielded, the coefficient of $F_{1}$ is 0.821 , and the coefficient of $F_{2}$ is 0.398 . And the regression equation is statistically significant, and the adjusted $\mathrm{R}$ square reaches

\begin{tabular}{|c|c|c|c|c|c|c|c|}
\hline & Unnormalized coefficient & Standard error & Normalization coefficient & $\mathbf{t}$ & Significant & Tolerance & VIF \\
\hline Constant & 0.159 & 0.089 & & 1.786 & 0.097 & & \\
\hline $\mathrm{F}_{1}$ & 0.821 & 0.096 & 0.819 & 8.545 & 0.000 & 0.999 & 1.001 \\
\hline $\mathrm{F}_{2}$ & 0.398 & 0.089 & 0.428 & 4.466 & 0.001 & 0.999 & 1.001 \\
\hline $\mathrm{R}^{2}$ & 0.862 & & & & & & \\
\hline
\end{tabular}
0.862. Specific data are shown in table 7.

Table 7. The results of equation (5).

That is to say, there can be a linear relationship between the dependent variable and the independent variable with a high degree of fit. Then the above regression results can be brought into equations (3) and (4), and the final regression coefficients

\begin{tabular}{|c|c|c|c|c|c|c|c|}
\hline \multirow{2}{*}{$\begin{array}{l}\text { Influence } \\
\text { Factors }\end{array}$} & \multicolumn{2}{|c|}{ R\&D Investment } & \multirow{2}{*}{$\begin{array}{l}\text { Economic } \\
\text { Structure } \\
\text { Industrial } \\
\text { Structure } X_{3}\end{array}$} & \multicolumn{2}{|l|}{ Infrastructure } & \multirow{2}{*}{$\begin{array}{l}\text { Openness } \\
\text { Foreign Direct } \\
\text { Investment } X_{6}\end{array}$} & \multirow{2}{*}{$\begin{array}{l}\text { Innovation Policy } \\
\text { Government's } \\
\text { Supporting Policy } X_{7}\end{array}$} \\
\hline & $\begin{array}{l}\text { R\&D } \\
\text { expenditures } \\
\text { Input } X_{1} \\
\end{array}$ & $\begin{array}{l}\text { R\&D Personnel } \\
\text { Input } X_{2}\end{array}$ & & $\begin{array}{l}\text { Cargo } \\
\text { Transportation } \\
\text { Carrier } X_{4} \\
\end{array}$ & $\begin{array}{l}\text { information } \\
\text { knowledge Carrier } X_{5}\end{array}$ & & \\
\hline $\begin{array}{l}\text { Regression } \\
\text { Coefficients }\end{array}$ & 0.115 & 0.100 & 0.269 & 0.167 & 0.292 & 0.198 & 0.156 \\
\hline
\end{tabular}
of each impact factor can be obtained, shown in Table 8 .

Table 8. Influence Factors Regression Coefficients Result. 
It can be seen from Table 7 that the regression coefficients of all influencing factors are positive, indicating that R\&D investment, economic structure, infrastructure, openness, and innovation policies all have positive effects on the innovation output of Qingyuan's regional innovation system. The following is a detailed analysis of each influencing factor.

The impact of infrastructure on the output of Qingyuan's regional innovation system accounts for a large proportion. For each $1 \%$ increase in traffic logistics carriers, the corresponding output level will increase by $0.167 \%$; for each $1 \%$ increase in information knowledge carriers, the corresponding output level will increase by $0.292 \%$, accounting for the largest proportion of all influencing factors. It shows that a more perfect transportation logistics and a more sound information sharing and communication network will be brought by the infrastructure upgrade. It plays an important role in improving the technological output capacity of Qingyuan. Further, the integration of Guangzhou-Qingyuan, Shenzhen-Qingyuan Enterprise Cooperation, and Qingyuan's active integration into Guangdong-Hong Kong-Macau Greater Bay Area, and the establishment of a link between Qingyuan and the Bay Area's scientific and technological information will enhance the infrastructure level of Qingyuan and improve Qingyuan's corporate groups benefited by absorbing foreign high-tech knowledge information and improving their own scientific and technological output.

The economic structure also plays an important role in the scientific and technological output of Qingyuan. For every $1 \%$ increase in industrial structure, the level of science and technology output in Qingyuan will increase by $0.269 \%$. Heavy industry is an important yardstick for economic development, many of which include high technology and cutting-edge technology. The technological innovation components in the production of heavy industry enterprises in Qingyuan are insufficient. The science and technology investment and innovation output chain have not formed into a scale system. The development of heavy industry still has a strong driving effect on regional innovation output.

The degree of openness to the outside world has a strong effect on the improvement of Qingyuan's regional innovation system. For every $1 \%$ increase in the actual use of foreign direct investment, the output of science and technology innovation in Qingyuan will be increased by $0.198 \%$, indicating that further opening up to the outside world and improving the efficiency of foreign investment funds will significantly increase the level of technological innovation. The reason may be that Qingyuan is located in the northwestern part of Guangdong. There are still some geographical isolation from those economic areas that is open to the outside world. There is still strong demand and absorption capacity for foreign direct investment and international advanced technology. With the gradual improvement of the development of coastal zones such as Shenzhen and the expansion of the Guangzhou economy to the periphery, Qingyuan will further enjoy the technological level and innovation capability improvement brought about by opening up.

The support of innovation policy also has a certain role in promoting regional innovation output in Qingyuan. For every $1 \%$ increase in the level of science and technology expenditures in government finance, the output capacity of innovation will increase by $0.156 \%$, indicating that the demand for government financial support by existing technology innovation enterprises in Qingyuan is still large, and that some enterprises face certain insufficient funds. Issues such as limited investment in scientific research exist. However, with the gradual implementation of "Ten Incentives for Science and Technology Innovation" in Qingyuan, the enterprise's innovation output capacity will be further upgraded.

R\&D investment measures the investment of $R \& D$ expenditure and R\&D personnel in industrial enterprises above designated size. However, compared with other influencing factors, R\&D investment has little impact on the regional innovation output of Qingyuan, and the impact coefficient is only about 0.1 . It can be seen that the technological strength of industrial enterprises above designated size in Qingyuan is weak, and the efficiency of R\&D investment and output is low. It may be because most large and medium-sized enterprises have not formed a strong enterprise $R \& D$ team and capital utilization chain, and have not formed effective R\&D Input-output system. It shows that the technology research and development efficiency of Qingyuan needs to be strengthened.

\section{Research Conclusions and Recommendations}

This paper establishes a regression model through the economic data of Qingyuan from 2001 to 2017, and analyzes the impact of various factors on the regional innovation system of Qingyuan. The main conclusions are as follows: (1) R\&D investment, economic structure, infrastructure, openness, and innovation policy support all have a significant positive impact on regional innovation output capacity. This is also the same as the conclusion of the existing literature [6-8]. Among them, infrastructure, economic structure and degree of opening to the outside world are the most important influencing factors. Considering that Qingyuan's existing industrial structure is still dominated by traditional manufacturing and the stock of new types of enterprises is relatively small, Qingyuan government's science and technology funding has moderate impact and research and development investment has relatively weak impact compared with other studies. (2) The impact of infrastructure, opening up and economic structure is relatively large, indicating that Qingyuan is still in the initial stage of industrialization and Technologicalization. The transportation logistics, the dissemination of information knowledge, the development of heavy industry, and the use of foreign investment are of great significance. The level of opening up and connectivity of Qingyuan needs to be strengthened. (3) The 
development of large and medium-sized enterprises in Qingyuan is still guided by capital investment. The knowledge and information learning ability needs to be strengthened, and the efficiency of scientific research input and utilization needs to be further improved.

In response to the above data and conclusions, the most important problem in Qingyuan is to actively introduce new industries and high-tech enterprises to change the local industrial structure dominated by agriculture and traditional manufacturing. The article aims at these problems and proposes the following suggestions: (1) Qingyuan should grasp the major opportunities such as Guangzhou-Qingyuan integration, Shenzhen-Qingyuan enterprise cooperation, Guangdong-Hong Kong-Macau Greater Bay Area construction, and actively integrate into the economic zone of Guangzhou-Shenzhen-Hong Kong as the axis. The economic zone will further enjoy the benefits brought about by the relocation of the reform and opening up from the coastal areas to the inland areas. Qingyuan will continue to expand the level of opening up to the outside world, actively absorb good foreign capital and international advanced technology, strengthen contact with the central cities of Guangdong, Hong Kong and Macao, gradually improve the transportation and logistics infrastructure between Guangzhou and Shenzhen, and upgrade information exchange technology to form a knowledge sharing network. (2) Qingyuan should actively implement the construction of Qingyuan Industrial Park, and appropriately increase the proportion of heavy industry as well as the scientific and technological content of enterprises. It should also improve the introduction process of high-tech enterprises, especially increase policy support in key industries such as information industry, pharmaceutical manufacturing, electronics and communication equipment manufacturing, and electronic computer industry. (3) Qingyuan municipal government should actively assist local enterprises above designated size to set up their own scientific research team, forming a complete path from knowledge and information learning, scientific and technological research development to product output innovation, it also need to improve the utilization efficiency of scientific research funds, and gradually transform the economic development way from capital-driven to knowledge-driven type.

\section{Acknowledgements}

We thank 2018 Qingyuan Science and Technology Plan Project - Construction of Open Industrial Innovation System under the Background of Urban Function Division (2018A011); 2019 Guangzhou Academy of Social Sciences Youth Project - Coordinated Development of Guangdong-Hong Kong-Macao Greater Bay Area Based on Specialized Division of Urban Agglomeration Functions (19QN007). The 65th China Post-doctoral Science Batch of Projects Funded by China Post-doctoral Science Foundation (2019M650194): Research on Heterogeneous Enterprises' Import and Export Decisions under the Background of Trade
Liberalization.

\section{References}

[1] Cooke P. Regional innovation systems: Competitive regulation in the new Europe [J]. Geoforum, 1992, 23 (3): 365-382.

[2] Cooke P. Regional Innovation Systems: The Role of Governance in the Globalized World [M]. London: UCL Press, 1996.

[3] Asheim B T, Isaksen A. Location, agglomeration and innovation: Towards regional innovation systems in Norway? [J]. European Planning Studies, 1997, 5 (3): 299-330.

[4] Chaoqing Yuan, Sifeng Liu. The Maturity of Regional Innovation System and Its Impact on Innovation Input-Output Efficiency-Based on the Research of 31 Provinces in China [J]. China Soft Science, 2013 (03): 101-108.

[5] Song Wang, Shuhua Hu, Renyan Yan. Theoretical Source and Framework of Regional Innovation System [J]. Science Research, 2013, 31 (03): 344-349+436.

[6] Triguero A, Córcoles D. Understanding innovation: An analysis of persistence for Spanish manufacturing firms [J]. Research Policy, 2013, 42 (2): 340-352.

[7] Frank A G, Cortimiglia M N, Ribeiro J L, et al. The effect of innovation activities on innovation outputs in the Brazilian industry: Market-orientation vs. technology-acquisition strategies [J]. Research Policy, 2016, 45 (3): 577-592.

[8] Shulin Liu, Lingfei Tian. The Impact of R\&D Investment from Different Industries on Regional Innovation Output [J]. Science and Technology Progress and Countermeasures, 2019, 36 (04): 33-39.

[9] Xibao Li. China's regional innovation capacity in transition: An empirical approach [J]. Research Policy, 2009, 38 (2): 338-357.

[10] Shulin Liu, Zhijian Hu. Distribution and Causes of Regional Innovation Capability in China [J]. Scientific Research, 2002 (05): 550-556.

[11] Cook P, Boekholt P, Tödtling, Franz, et al. The Governance of innovation in Europe: regional perspectives on global competitiveness [M]. London: Pinter, 2000: 37.

[12] Wei SU, Zhou-zhou Lin. Study on the Spatial Effect and Influencing Factors of Regional Innovation Activities [J]. Quantities Economics \& Economics Research, 2017, 34 (11): 63-80.

[13] Wenguang Bo. The Impact of Foreign Direct Investment on China's Technology Innovation-Based on Regional Level Research [J]. Financial Research, 2007 (06): 4-17.

[14] Fengqi Sun, Zhiwei Tian. The Way to Improve Regional Innovation Efficiency: Selective Protection or Fully Open [J]. Scientific and Technological Progress and Countermeasures, http://kns.cnki.net/kcms/detail/42.1224.42.1224.G3.20190329. 0854.012.html.

[15] Xianghua Wang, Liping $\mathrm{Fu}$, Yongjun He. An Empirical Analysis of Government Science and Technology Input Benefits in China's Regional Innovation System [J]. Scientific Management Research, 2011, 29 (01): 1-5. 
[16] Guoming Xian, Wenguang Bo. The Impact of Foreign Direct Investment on the Technological Innovation of Chinese Enterprises-Based on Analysis at the Regional Level [J]. Economic Sciences, 2006 (03): 106-117.

[17] Runxiu Hou, Jiancheng Guan. The Influence of Foreign Direct Investment on China's Regional Innovation Capability [J]. China Soft Science, 2006 (05): 104-111.

[18] Buesa M, Heijs J, Mónica Martínez Pellitero, et al.. Regional systems of innovation and the knowledge production function: the Spanish case [J]. Technovation, 2006, 26 (4): 463-472.
[19] Xianhui Wu, Haiyan Wu, Qiang Lu, Wu Yang. An Empirical Study on the Influencing Factors of China's Regional Innovation System-Taking Shenzhen as an Example [J]. Science and Technology Progress and Policy, 2011, 28 (07): 26-31.

[20] Li Yan, Jun Zhang. An Empirical Study on the Impact Factor Analysis Model of Regional Innovation System-Taking Wuhan as an Example [J]. Economic Issues, 2011 (06): 119-122.

[21] Zhang Aihua. Construction of Evaluation Index System for Regional Innovation [J]. Statistics and Decision, 2017 (24): 51-53. 